\title{
Hubungan antara Harga Diri dan Body Image dengan Online Self-Presentation pada Pengguna Instagram
}

\author{
Lalu Arman Rozika ${ }^{1}$, Neila Ramdhani ${ }^{2}$ \\ Fakultas Psikologi Universitas Gadjah Mada
}

\begin{abstract}
Abstrak. This research departs from the results of previous studies in the field of cyberspace, which shows differences in one's behavior when in the world of the internet and in the real world. The Internet has now become the most widely used communication tool. The purpose of this study is to see what psychological factors that affect a person when behaving in the internet world. Subjects in this study were 389 users of Instagram users who filled out the research questionnaire online. Measuring tool in this research is a self-esteem scale, body image scale, and self-presentation online scale. While the analysis method used is Multiple Linear Regression Analysis. The results showed that there is a positive relationship between self-esteem and body image with online self-presentation. Self-esteem and body image can predict self-presentation online with a significance level of $\mathrm{p}<0.05$. Effective contribution of self esteem and body image variable to selfpresentation online variable is $3.8 \%$.
\end{abstract}

Keywords: body image, self esteem, online self-presentation

\begin{abstract}
Abstrak. Penelitian ini berawal dari hasil penelitian-penelitian sebelumnya dalam bidang cyberspace, yang menunjukkan perbedaan perilaku seseorang ketika berada dalam dunia internet dan dalam dunia nyata. Internet kini telah menjadi alat komunikasi yang paling banyak digunakan. Tujuan penelitian ini adalah untuk melihat faktor psikologis apa yang memengaruhi seseorang ketika berperilaku dalam dunia internet. Subjek dalam penelitian ini adalah 389 orang pengguna Instagram yang mengisi kuesioner penelitian secara online. Alat ukur dalam penelitian ini adalah berupa skala harga diri, skala body image, dan skala online self-presentation. Sedangkan metode analisis yang digunakan adalah Multiple Linear Regresion Analysis. Hasil penelitian menunjukkan bahwa terdapat hubungan positif antara harga diri dan body image dengan online self-presentation. Harga diri dan body image dapat memprediksi online self-presentation dengan taraf signifikansi $p<0,05$. Sumbangan efektif dari variabel harga diri dan body image terhadap variabel online self-presentation yakni sebesar 3,8\%.
\end{abstract}

Kata kunci: harga diri, body image, online self-presentation

Internet adalah salah satu media komunikasi, dan dengan segala kelebihannya, pengguna internet dapat dengan

\footnotetext{
${ }^{1}$ Korespondensi mengenai isi artikel ini dapat dilakukan melalui armanrozika@mail.ugm.ac.id

2 Atau melalui neila_psi@ugm.ac.id
}

mudahnya mengunggah kata-kata, gambar, video dan juga foto-fotonya di internet. Salah satu ciri dari komunikasi lewat internet adalah online disinhibition. Online disinhibition adalah berkurangnya atau bahkan menghilangnya perasaan 
cemas dan malu ketika berkomunikasi melalui internet (Suler, 2004).

Online disinhibition membuat pengguna internet menjadi tidak ragu untuk mengungkapkan pendapatnya, bahkan pendapat yang diutarakan secara kasar dan dapat melecehkan orang lain. Bryant (2001), dalam analisis teoretis dan filosofisnya terhadap tema cyberspace, menyatakan bahwa cyberspace tak ubahnya sebuah tempat tersendiri yang juga memiliki karakter tempat, jarak, luas, dan arahnya tersendiri.

Penelitian dan kajian teori menyangkut internet dan khususnya media sosial seringkali menjadikan media sosial sebagai "kambing hitam" atas berbagai macam perilaku online. Media sosial dapat menyebabkan penurunan kepercayaan diri (Sharma \& Sahu, 2013). Media sosial dapat membuat individu menjadi adiksi terhadapnya, dan dapat mengganggu kesehariannya (Abdulahi, Samadi, Garleghi, 2014; El-Khouly, 2015). Media sosial dapat memperburuk relasi, seperti anekdot yang sering terdengar, internet mendekatkan yang jauh namun menjauhkan yang dekat (Akbiyik, 2013).

Penelitian yang dilakukan di Indonesia juga masih banyak yang hanya berfokus pada dampak internet. Studi kualitatif deskriptif yang dilakukan oleh Khairunnisa (2014) pada siswa SMAN 2 Tenggarong terkait penggunaan instagram, menunjukkan hasil bahwa penggunaan Instagram dapat menyebabkan perilaku konsumtif yang negatif, seperti membeli barang-barang yang sebenarnya tidak menjadi prioritas utama. Penelitian yang dilakukan oleh Syamsoedin, Bidjuni, dan Wowiling (2015) juga menunjukkan dampak negatif media sosial pada siswa SMAN 9 Manado.

Dunia cyberspace memang merupakan tema yang relatif baru. Kajian penelitian psikologi perlahan-lahan sudah mulai membahas dunia cyberspace, salah satunya yakni yang menyangkut selfesteem atau harga diri. Penelitian yang cukup menarik terkait cyberspace dan harga diri dilakukan oleh Gonzalez dan Hancock (2011) yang meneliti pengaruh berada di depan facebook (exposure to facebook) terhadap harga diri. Hasil eksperimen tersebut menunjukkan bahwa Facebook dapat memberikan keleluasaan kepada partisipan untuk memilih selfpresentation seperti apa yang akan ditunjukkan kepada teman facebook-nya, tergantung dari self-ideal yang dimiliki. Hal tersebut yang kemudian meningkatkan harga diri partisipan ketika sedang berada di depan layar Facebook.

Penelitian yang mencoba menyingkap faktor psikologis yang memengaruhi perilaku individu di dunia online masih tergolong sedikit. Beberapa di antaranya yakni studi cyberspace yang dilakukan oleh Stefanone, Lackaff, dan Rosen (2011) pada 311 mahasiswa yang menggunakan Facebook untuk bertukar foto (photo sharing), hasilnya menunjukkan hubungan yang signifikan antara contingencies self-worth (CSW) dengan intensitas bertukar foto. CSW merupakan dimensi lain dari self-estem yang di dalamnya berisi keinginan individu agar terlihat baik oleh orang lain (selfpresentation goal). Dari penelitian tersebut dapat dilihat bahwa semakin ingin terlihat baik, seseorang akan semakin sering menimbulkan kesan positif atas dirinya di dunia online.

Mehdizadeh (2010) juga membuktikan bahwasanya self-promoting pada media sosial Facebook seperti mengupdate status, mengunggah foto, dan menulis catatan, intensitasnya lebih tinggi pada subjek penelitian yang memiliki nilai harga diri yang rendah. Penelitian tersebut 
menunjukkan bahwa penggunaan Facebook berhubungan dengan keinginan individu untuk menampilkan kesan diri atau presentasi dirinya kepada orang lain.

Jejaring sosial dapat digunakan untuk memperlihatkan foto-foto yang dapat disunting terlebih dahulu oleh penggunanya. Hal tersebut berkaitan dengan body image individu. Body image adalah persepsi dan sikap individu terhadap tubuhnya sendiri, terutama penampilannya secara fisik (Cash, Fleming, Alindogan, Steadman, \& Whitehead, 2002b). Internet memberikan kemudahan bagi seseorang untuk menampilkan citra diri atau gambaran fisik yang ingin ditampilkannya secara online, individu dapat memilih, menyeleksi, dan menyunting terlebih dahulu gambaran fisik seperti apa yang akan ditampilkannya di internet. Individu dapat menampilkan presentasi diri apapun yang ia inginkan di internet.

Goffman (1956) menjelaskan bahwa presentasi diri adalah upaya seseorang untuk menimbulkan kesan dirinya terhadap orang lain. Upaya menimbulkan kesan tersebut adalah dengan cara menampilkan diri di hadapan orang lain sesuai dengan yang diinginkan. Kesan yang ditampilkan seseorang terhadap orang lain tersebut melalui tahapan seleksi atau tahap persiapan terlebih dahulu. Goffman (1956) mengibaratkan presentasi diri sebagai sebuah panggung drama atau panggung sandiwara yang memiliki front stage dan back stage.

Penelitian ini adalah penelitian mengenai komunikasi internet, maka peneliti rasa perlu untuk memaparkan penjelasan mengenai sifat-sifat komunikasi internet. Sifat-sifat yang dibawa atau yang menyertai komunikasi online antara lain keleluasaan pengguna untuk menjadi anonim (dissociative anonimity), tidak terlihat (invisibility), rentang waktu komunikasi yang tidak sama (asycnhronity), berkurangnya isyarat verbal (solipsistic introjection), keleluasaan mengontrol konten diri yang akan ditampilkan (dissociative imagination), dan berkurangnya aturan-aturan dan norma sosial (minimization of status and authority) (Suler, 2004). Di dalam internet, seseorang tidak lagi memiliki batasan-batasan norma yang sama dengan dunia offline karena seseorang dapat menjadi anonim di internet.

Oxford Dictionary

mengartikan self sebagai "your own nature; your personality". Sedangkan dalam terjemahan bahasa Indonesianya, self dapat diartikan menjadi diri. Sementara itu, presentation adalah "act of showing something or giving something to somebody" (Oxford Dictionary, 2003). Diterjemahkan ke dalam bahasa Indonesia, selfpresentation dapat diartikan sebagai sebuah tindakan untuk menunjukkan kesan diri terhadap orang lain.

$$
\text { Jones dan Pittman }
$$

menyatakan bahwa self-presentation adalah sebuah usaha untuk menimbulkan kesan terhadap orang lain dan dipengaruhi oleh berbagai macam motif tertentu. Motifmotif tersebut antara lain seperti keinginan untuk dianggap menjadi orang baik dan disukai oleh orang lain, keinginan untuk menunjukkan power atau kekuatannya kepada orang lain, dan juga keinginan untuk dianggap menjadi orang yang berwibawa (Jones \& Pittman, 1982). Lewis dan Neighbors (2005) menganggap self-presentation sebagai upaya untuk memengaruhi orang lain. Pada gilirannya, upaya untuk memengaruhi orang lain tersebut berdampak pada konsep diri individu dan juga perasaan akan keberhargaan (self-worth) (Lewis \& Neighbors, 2005). 
Berdasarkan beberapa uraian di atas, dapat disimpulkan bahwa self-presentation adalah perilaku menampilkan kesan yang ingin ditampilkan kepada orang lain. Jones dan Pittman (1982) menjelaskan terdapat lima bentuk strategi selfpresentation yang masing-masing dibedakan oleh tujuan dan motifnya. Kelima strategi self-presentation tersebut yaitu: ingratiation, intimidation, self promotion, exemplification, supplication. Perilaku ingratiation adalah perilaku ketika seorang individu ingin disukai oleh orang lain, seperti misalnya dianggap sebagai orang yang humoris, hangat, dan bersahabat. Individu akan berusaha menampilkan kesan yang kira-kira akan membuat dirinya disukai oleh orang lain.

Intimidation adalah kebalikan dari ingratiation. Ingratiation adalah upaya menampilkan kesan agar disukai, sedangkan intimidation adalah upaya menampilkan kesan berbahaya kepada orang lain.

Self promotion adalah strategi selfpresentation ketika individu berusaha menampilkan kesan bahwa dirinya mampu dan kompeten, baik dalam hal-hal yang bersifat umum seperti cerdas dan pintar maupun dalam hal-hal yang spesifik seperti bermain piano atau bermain sepak bola.

Self promotion adalah strategi menampilkan kesan kompeten dan mampu, sementara itu exemplification adalah perilaku ketika individu berupaya menampilkan kesan dirinya sebagai orang yang baik hati.

Strategi self-presentation yang kelima adalah supplication, yaitu perilaku ketika individu berusaha menampilkan kesan bahwa dirinya lemah, salah satunya yakni dengan memperlihatkan kelemahannya kepada orang lain.
Penelitian mengenai online selfpresentation masih relatif baru, dan penelitian-penelitian yang telah dilakukan pun menunjukkan hasil yang berbedabeda. Online self-presentation adalah perilaku dalam dunia online, maka penelitian ini menjelaskan faktor yang memengaruhi self-presentation secara khusus di dunia online. Beberapa faktor yang membuat seseorang berperilaku sedemikian rupa di dunia online adalah sebagai berikut:

Pertama, sesuai dengan teori selfpresentation yang dikemukakan oleh Jones dan Pittman (1982), bahwa kelima bentuk self-presentation itu sendiri telah menjelaskan tujuan atau faktor apa yang memengaruhi seseorang melakukan presentasi diri, kelimanya yakni ialah; ingratiation (keinginan untuk disukai oleh orang lain), intimidation (keinginan untuk menunjukkan kuasa atas orang lain), exemplification (keinginan untuk dianggap sebagai orang yang dermawan), selfpromotion (keinginan untuk dihargai oleh orang lain atas kemampuan dan keahlian yang dimiliki), dan supplication (keinginan untuk mendapatkan simpati dari orang lain).

Kedua, popularitas. Raymer (2015) membuktikan bahwa intensitas penggunaan media sosial berbanding lurus dengan harga diri, namun terdapat mediator di antara hubungan harga diri dengan intensitas penggunaan media sosial. Individu dengan harga diri rendah menggunakan media sosial agar dirinya diterima oleh lingkungan sosialnya, sedangkan individu dengan harga diri tinggi menggunakan media sosial untuk menunjang popularitasnya.

Ketiga, harga diri. Rosenberg, Schooler, Carmi, dan Rosenberg (1995) menyatakan bahwa harga diri adalah sikap individu baik positif maupun negatif 
terhadap dirinya. Beberapa penelitian mengungkapkan bahwa penggunaan media sosial seperti facebook dapat memengaruhi harga diri seseorang. Penggunaan facebook dapat menurunkan harga diri karena individu cenderung membandingkan dirinya dengan orang lain atau teman Facebook-nya (Leif et al, 2012). Sebaliknya, berada di hadapan Facebook juga ternyata membuat harga diri menjadi naik (Gonzalez dan Hancock, 2011). Hubungan antara penggunaan internet terutama media sosial dengan harga diri dapat dilihat dari penelitian Mehdizadeh (2010) yang menemukan bahwa individu dengan harga diri yang rendah berusaha menaikkan harga diri dirinya dengan menggunakan media sosial karena media sosial dapat menjadi sebuah wadah di mana individu dapat membentuk citra diri dan menampilkan kesan diri yang diinginkannya.

Keempat, body image. Pengguna internet tentu saja tidak terlihat oleh pengguna lainnya. Sekalipun komunikasi yang dilakukan adalah berbasis video, tetap saja pengguna internet tidak secara langsung bertatap muka, apalagi jika menggunakan komunikasi berbasis teks semata. Individu memiliki peluang untuk membentuk presentasi diri yang diinginkan, karena ia tidak terlihat (invincible). Keleluasaan pembentukan presentasi diri tersebut menjadi salah satu faktor presentasi diri seseorang di dunia maya yang berkaitan dengan body image idealnya (Mehdizadeh, 2010).

Komunikasi internet, khususnya yang berbasis teks, tidak menghadirkan lawan bicara secara langsung, dengan demikian hal tersebut menimbulkan proyeksi dan imajinasi pada masingmasing individu, tentang bagaimana gaya bicara dan intonasi dari lawan bicaranya (Suler, 2004).
Body image atau yang dalam terjemahan bahasa Indonesia dapat diartikan menjadi citra tubuh, menyangkut tentang bagaimana individu menilai penampilan fisiknya, serta kepuasan dan penerimaan terhadap tubuhnya. Body image merupakan tema penelitian yang cukup familiar dalam ranah penelitian psikologi. Banyak ahli yang sudah meneliti dan memberikan penjelasan mengenai tema body image.

Hogan dan Strasburger (2009) menyatakan bahwa body image adalah persepsi individu terhadap tubuhnya sendiri serta refleksi dan evaluasi terhadap tubuh dan penampilan fisiknya. Body image berkaitan dengan bagaimana individu menggambarkan dan memberikan evaluasi terhadap tubuhnya sendiri.

Body image adalah suatu perkiraan dan evaluasi individu terhadap tubuh fisiknya di dalam hubungannya dengan norma-norma sosial dan penilaian dari orang lain. Cash (2004) menjabarkan bahwa body image merupakan penilaian menyeluruh individu terhadap tubuhnya, serta tingkat kepuasan individu terhadap penampilannya. Selain itu, Cash (2002a) juga mengenmbangkan alat ukur untuk body image yakni Multidimentional Body-Self Relations Questionnaire-Appearance Scales (MBSRQ-AS).

Banfield dan McCabe (2002) menyatakan bahwa body image adalah serangkaian penilaian terhadap tubuh atau penampilan secara fisik yang juga dapat disertai oleh kecemasan seperti ketakutan menjadi gemuk, ketakutan menjadi terlalu kurus, dan juga ketidakpuasan terhadap tubuh.

Pompili, Girardi, Tatarelli, Ruberto, dan Tatarelli (dalam Hamilton, 2008) menemukan bahwa ketidakpuasan terhadap bentuk tubuh dapat 
menyebabkan dan mengarahkan pada gangguan makan, dan membuat seseorang menjadi depresi dan dapat berujung pada tindakan bunuh diri. Hamilton (2008) menyatakan bahwa memang kehidupan tengah dikelilingi dan dipenuhi oleh "perfect body image type" atau tipe tubuh yang sempurna. Body image ideal yang ditampilkan lewat internet sekalipun tidak sama dengan real-self individu, dapat membuat individu berani mengungkapkan dirinya (Gonzalez \& Hancock, 2011).

Harga diri adalah salah satu topik yang sering dibahas dalam kajian psikologi. Wajar saja, kajian material psikologi adalah manusia, dan kajian mengenai manusia tentu tidak dapat terlepas dari self atau diri manusia itu sendiri. Rosenberg et al (1995) menjelaskan bahwa harga diri adalah penilaian dan sikap individu secara menyeluruh terhadap dirinya sendiri, mulai dari penilaian yang bersifat negatif sampai positif.

Menurut Branden (2001) harga diri adalah penilaian dan penghakiman terhadap diri sendiri, bagaimana individu melihat dan menilai serta menghakimi dirinya secara keseluruhan. Penghakiman atau judgement tersebut juga dapat bersifat negatif sampai positif. Lebih lanjut Cast dan Burke (2002) menyatakan bahwa harga diri adalah bagaimana individu menghargai dirinya sendiri.

Tafarodi dan Swann (2001) menjelaskan bahwa harga diri adalah sebuah variabel psikologis yang berisi dua dimensi, yakni: (1) dimensi self-competence, yaitu dimensi yang berkaitan dengan bagaimana individu memandang kemampuan dirinya, apakah individu menganggap dirinya adalah orang yang kompeten dan mampu atau tidak, (2) dimensi self-liking, yaitu dimensi yang berkaitan dengan bagaimana individu memandang dirinya, apakah individu menyukai dirinya atau tidak.

$$
\text { Ryan dan Brown (2003) juga }
$$

menyatakan bahwa harga diri adalah perilaku menghargai diri sendiri, dapat dicontohkan dalam perilaku nyata seperti berpikir positif, merasa bahagia, menjadi optimis dan berusaha mencapai kesuksesan.

Berdasarkan uraian di atas dapat disimpulkan bahwa harga diri adalah bagaimana individu menghargai dan menilai dirinya sendiri secara keseluruhan baik secara positif maupun negatif. Tafarodi dan Swann (2001) mengemukakan dua aspek harga diri yakni self-competence dan self-liking. Selfcompetence adalah bagaimana individu menilai dirinya berdasarkan pengalaman yang ia miliki. Penilaian tersebut dimulai dari rentang negatif sampai dengan positif mengenai diri sebagai sumber dari kekuatan. Self-competence adalah kepercayaan individu bahwa dirinya lah yang membuat perubahan atau keinginankeinginannya tercapai.

Self-liking adalah penilaian individu terhadap dirinya sendiri, apakah ia memandang dirinya sebagai orang yang baik atau orang yang buruk. Self-liking terkait dengan penilaian sosial. Penilaian sosial yang dimaksud bukanlah penilaian sosial seperti bagaimana orang lain atau lingkungan menilai individu, akan tetapi bagaimana individu mengambil nilai-nilai sosial untuk menilai dan mengevaluasi dirinya sendiri (Tafarodi \& Swann, 2001).

Harga diri dan body image secara bersama-sama dapat memprediksi online Self-Presentation pada pengguna Instagram. Maka hipotesis penelitian yang diajukan adalah semakin tinggi harga diri dan semakin tinggi body image, maka akan semakin rendah online self-presentation. 
Semakin rendah harga diri dan semakin rendah body image, maka akan semakin tinggi online self-presentation.

\section{Metode}

\section{Rancangan Penelitian}

Penelitian ini adalah penelitian kuantitatif dan diolah menggunakan pendekatan statistik. Metode statistik yang dipergunakan yakni teknik MRA (Multiple Regression Analysis). Peneliti menggunakan bantuan program SPSS for windows untuk membantu mempermudah penghitungan dan analisis terhadap data penelitian.

\section{Subjek Penelitian}

Subjek penelitian ini adalah 389 orang pengguna Instagram yang peneliti dapatkan dengan menggunakan metode incidental sampling. Subjek dalam penelitian ini mengisi kuesioner penelitian secara online melalui aplikasi online yang disediakan oleh Google, yakni Google forms. peneliti buat berdasarkan teori selfpresentation yang dikemukakan oleh Jones dan Pittman (1982). Skala harga diri merupakan alat ukur yang peneliti adaptasi dari skala yang dikembangkan oleh Tafarodi dan Swann (2001), sedangkan skala body image adalah skala yang peneliti buat berdasarkan teori body image yang dikemukakan oleh Cash (2002a).

\section{Hasil}

\section{Deskripsi Subjek Penelitian}

Jumlah subjek penelitian setelah peneliti mengeluarkan subjek yang tidak mengisi kuesioner secara lengkap adalah 389 orang, dengan wanita sebanyak 283 orang, dan pria sebanyak 106 orang.

\section{Tabel 1.}

\begin{tabular}{|c|c|c|}
\hline Jenis Kelamin & Frekuensi & Pesentase \\
\hline Wanita & 283 & 72,7 \\
\hline Pria & 106 & 27,3 \\
\hline Total & 389 & 100 \\
\hline
\end{tabular}

Tabel 2.

Gambaran Umum Hasil Skor Variabel-variabel Penelitian

\begin{tabular}{lllllll}
\multicolumn{2}{c}{ Statistik } & \multicolumn{2}{c}{ Online Self-Presentation } & \multicolumn{2}{c}{ Harga Diri } & \multicolumn{2}{c}{ Body Image } \\
& Hipotetik & Empirik & Hipotetik & Empirik & Hipotetik & Empirik \\
\hline Skor Min. & 13 & 13 & 14 & 30 & 20 & 32 \\
Skor Max. & 65 & 65 & 70 & 70 & 100 & 100 \\
Mean & 39 & 41,61 & 42 & 48,10 & 60 & 64,97 \\
Standar Deviasi & 8,66 & 8,28 & 9,33 & 7,10 & 13,33 & 10,80 \\
\hline
\end{tabular}

\section{Cara Pengumpulan Data}

Data dalam penelitian ini diambil dengan menggunakan instrumen alat ukur yang berupa skala. Alasan penggunaan skala dalam penelitian ini yaitu karena skala psikologi mampu mengukur indikator perilaku, selain itu respon jawaban subjek tidak dikategorikan menjadi benar dan salah. Skala online self-presentation dalam penelitian ini merupakan alat ukur yang

\section{Deskripsi Data Penelitian}

Sesuai dengan gambaran umum tentang skor online self-presentation, harga diri, dan body image tersebut, kemudian dibuat kategorisasi. Menurut Azwar (2008), tujuan kategorisasi adalah untuk menempatkan individu ke dalam kelompok-kelompok yang terpisah secara 
berjenjang menurut suatu kontinum berdasarkan atribut yang diukur.

Berdasarkan rumus kategorisasi pada tabel 3, rentang skor pada online selfpresentation adalah 13 - 30,33 untuk kategori rendah, 30,34 - 47,65 untuk kategori sedang, dan 47,66 - 65 untuk kategori tinggi.

Tabel 3.

Rentang Nilai dan Kategorisasi

Skor Subjek Penelitian

\begin{tabular}{lc}
\hline \multicolumn{1}{c}{ Norma Kategorisasi } & Kategori \\
\hline$\mu+1 S D \leq x$ & Tinggi \\
$\mu-1 S D \leq x<\mu+1 S D$ & Sedang \\
$x<\mu-1 S D$ & Rendah \\
\hline $\begin{array}{l}\text { Keterangan: } \\
\mu: \text { Mean Skor }\end{array}$ & $x$ :Skor Subjek \\
$S D:$ Standar Deviasi Skor &
\end{tabular}

7,7\% subjek memiliki tingkat online self-presentation yang rendah, 69,9\% subjek berada pada kategori sedang, dan $22,3 \%$ subjek berada pada kategori tinggi. 2,05\% subjek memiliki tingkat harga diri yang rendah, $68,8 \%$ subjek berada pada kategori sedang, dan $29,04 \%$ subjek berada pada kategori tinggi. 4,62\% subjek memiliki tingkat Body Image yang rendah, 76,09\% subjek berada pada kategori sedang, dan 19,28\% subjek berada pada kategori tinggi. Hal tersebut menunjukkan bahwa pada saat penelitian dilakukan, body image subjek penelitian rata-rata berada pada kategori sedang.

Uji hipotesis dilakukan dengan analisis regresi berganda dengan menggunakan metode enter pada program SPSS v 20. Tujuan dari analisis ini adalah untuk melihat pengaruh dari variabel prediktor pada variabel kriterium. Sebelum melakukan analisis, data atau kasus outliers (pencilan) dikeluarkan terlebih dahulu. Jumlah data outliers setelah analisis casewise diagnostics yakni sebanyak sembilan kasus, dengan demikian total keseluruhan subjek untuk dianalisis dalam penelitian ini berjumlah $N=380$. Berdasarkan hasil pengujian regresi berganda didapatkan nilai $p<0,05$. Hasil tersebut menunjukkan bahwa online self-presentation dapat diprediksi berdasarkan harga diri dan body image dengan arah hubungan negatif, sehingga H1 ditolak.

Sumbangan efektif dari kedua variabel prediktor terhadap variabel kriterium secara bersama-sama dapat dilihat berdasarkan nilai koefisien determinasi $\left(R^{2}\right)$. Nilai koefisien determinasi $\left(R^{2}\right)$ yang diperoleh berdasarkan hasil analisis regresi sebesar 0,038 . Hal ini berarti bahwa variabel online self-presentation dapat dijelaskan oleh variabel harga diri dan body image sebesar $3,8 \%$. Sedangkan sisanya sebesar $96,2 \%$ dijelaskan oleh variabel lain di luar penelitian ini.

\section{Diskusi}

Model analisis yang digunakan dalam penelitian ini adalah teknik analisis regresi berganda, hasil analisis yang telah dilakukan terhadap data penelitian menemukan bahwa $H 1$ yang diajukan, tidak teruji kebenarannya. Hasil tersebut didapatkan dari hasil analisis regresi berganda dengan nilai $F_{\text {regresi }}=7,480$ dan $p<0,05$. Akan tetapi, arah hubungan yang didapatkan dari hasil analisis regresi adalah positif.

Hasil penelitian ini menunjukkan bahwa online self-presentation dapat diprediksi berdasarkan harga diri dan body image. Sumbangan efektif dari kedua variabel prediktor terhadap varibel kriterium secara bersama-sama dapat dilihat dari nilai koefisien determinasi $\left(R^{2}\right)$. Nilai koefisien determinasi $\left(R^{2}\right)$ yang 
diperoleh berdasarkan hasil analisis regresi yakni sebesar 0,038 . Hal ini berarti bahwa variabel online self-presentation dapat dijelaskan oleh variabel harga diri dan body image sebesar 3,8\%. Sedangkan sisanya sebesar 96,2\% dijelaskan oleh variabel lain yang tidak terdapat dalam penelitian ini.

Hasil penelitian ini bertolak belakang dengan hasil penelitian yang dilakukan oleh Mehdizadeh (2010), yang menyatakan bahwa individu dengan harga diri rendah memiliki intensitas yang lebih tinggi untuk menunggah foto (melakukan online self-presentation), sedangkan hasil penelitian ini menunjukkan bahwa harga diri rendah justru menjadi prediktor online selfpresentation yang rendah karena arah hubungan yang didapatkan dari hasil analisis regresi dalam penelitian ini adalah positif.

Hasil penelitian ini juga bertolak belakang dengan hasil penelitian yang dilakukan oleh Ikachoi, Mberia, dan Ndati (2015) dan Kircaburun (2016) yang menemukan hubungan negatif antara harga diri dengan penggunaan social media sehari-hari. Hasil penelitian tersebut menemukan bahwa individu dengan harga diri rendah cenderung memilih dunia internet untuk meningkatkan harga diri-nya.

Hasil penelitian ini bertolak belakang dengan penelitian yang dilakukan oleh Raymer (2015), yang menemukan bahwa body image rendah berhubungan dengan intensitas penggunaan social media Facebook yang semakin sering. Di samping itu, hasil analisis juga menunjukkan bahwa, secara parsial body image tidak dapat memprediksi online self-presentation karena hasil yang didapatkan setelah uji-t untuk variabel Body Image adalah $p>0,05$.
Harga diri adalah penilaian individu terhadap dirinya sendiri, baik secara positif maupun negatif (Branden, 2001; Tafarodi \& Swan, 2001). Harga diri yang rendah adalah penghakiman dan penilaian individu bahwa dirinya tidak kompeten, serta individu memandang dirinya sebagai seorang yang buruk. Media sosial, dalam hal ini dapat menjadi salah satu pelarian bagi individu dengan harga diri yang rendah.

Individu dengan harga diri rendah lebih memilih menolak kontak dengan dunia nyata dan memilih dunia maya di mana ia dapat menjadi siapa saja yang ia inginkan (Kircaburun, 2016). Temuan tersebut selaras dengan yang diutarakan oleh Suler (2004), bahwa dalam dunia internet, siapa saja dapat menampilkan dirinya menjadi apa saja yang ia inginkan karena berkurangnya aturan dan norma (minimization of status and authority) yang ada di dunia internet. Sebaliknya, penelitian ini membuktikan bahwa semakin tinggi harga diri dan body image individu, atau semakin baik penilaian seseorang terhadap dirinya dan penampilan fisiknya sendiri, maka online self-presentation individu tersebut juga menjadi semakin tinggi, atau dalam artian semakin sering ia mengunggah foto tertentu pada instagram.

Raymer (2015) menyebutkan bahwa individu dengan harga diri rendah menggunakan media sosial dengan tujuan agar ia diterima oleh orang lain (gain acceptance), sementara individu dengan harga diri tinggi menggunakan media sosial untuk menunjang popularitasnya. Keinginan untuk menjadi populer atau kebutuhan untuk menunjang popularitas tersebut dapat menjadi salah satu mediator yang dapat menjelaskan mengapa hasil penelitian ini berbeda dengan penelitian-penelitian sebelumnya. 
Media sosial Instagram memberikan kendali terhadap penggunanya untuk membuat akun menjadi privat atau tidak, jadi setiap akun yang tidak di-privacy akan dapat memiliki follower yang bahkan tidak dikenal sama sekali, sehingga akan memperbesar kemungkinan bahwa akun yang tidak di-privacy tersebut menggunakan Instagram demi menunjang popularitas. Dalam penelitian ini tidak terdapat kontrol terhadap variabel popularitas tersebut, sehingga terdapat kemungkinan bahwa subjek dalam penelitian ini memiliki kebutuhan untuk menunjang popularitas yang tinggi, sehingga menyebabkan arah hubungan harga diri dan online self-presentation menjadi positif.

Instagram adalah sebuah media sosial yang bukan hanya digunakan untuk kepentingan komunikasi atau sharing semata, akan tetapi juga terdapat unsur bisnis dan marketing di dalamnya. Akun instagram bukan lagi hanya digunakan secara personal, akan tetapi dipakai untuk menunjang kegiatan bisnis (profit oriented), seperti misalnya berjualan secara langsung pada halaman instagram, menjual shoutout (mempromosikan akun orang lain), dan juga endorse (mempromosikan produk orang lain). Dalam penelitian ini, peneliti tidak mengontrol pengguna Instagram yang memang menggunakan instagram secara personal dan yang menggunakan Instagram untuk berjualan. Sementara itu, ketiga aspek Online Self-Presentation yakni ingratiation (agar disukai orang lain), self promotion (mempromosikan diri), dan exemplification (agar dihormati orang lain) juga berlaku pada sisi bisnis. Sebuah produk tentu saja menginginkan agar konsumen menyukai produk tersebut, sebuah produk tentu dipromosikan, dan sebuah produk tentu saja menginginkan agar produknya dipercaya sebagai sebuah produk yang baik. Dengan demikian, peneliti berpendapat bahwa tidak adanya kontrol terhadap tipe pengguna Instagram tersebut membuat hasil penelitian ini berbeda dengan penelitian-penelitian sebelumnya.

Penelitian ini meneliti pengguna social media Instagram sebagai subjek, sementara penelitian lain banyak yang berfokus pada Facebook dan media sosial lainnya. Di samping itu, Instagram hanyalah salah satu dari sekian banyak media sosial yang ada. Penelitian ini tentu saja tidak lepas dari berbagai keterbatasan, antara lain keterbatasan pada pemilihan Instagram sebagai media sosial yang diteliti. Kondisi ini, seperti yang telah dijelaskan sebelumnya, akan membuat pengaruh prediktor terhadap kriterium penelitian menjadi kecil karena masih banyak media sosial lain yang dapat menjadi tempat online self-presentation individu, masih banyak media sosial lain yang dapat menjadi tempat individu melakukan presentasi diri. Oleh karena itu, pada penelitian-penelitian selanjutnya dengan tema yang sama diharapkan peneliti selanjutnya dapat meneliti media sosial yang lain. Selain itu, pada penelitian ini juga tidak membedakan antara subjek yang memiliki follower berupa orang-orang yang dikenalnya, dan subjek yang memiliki follower berupa orang-orang yang tidak dikenalnya.

\section{Kesimpulan}

Berdasarkan hasil analisis dan pembahasan yang telah dipaparkan pada bab-bab sebelumnya, terdapat beberapa kesimpulan, yakni, harga diri dan body image secara bersama-sama memprediksi online self-presentation sebesar 3,8\%. Berdasarkan hasil kategorisasi ketiga variabel penelitian, subjek cenderung 
berada pada kelompok sedang hingga tinggi pada masing-masing variabel penelitian.

\section{Kepustakaan}

Abdulahi, A., Samadi, B., \& Gharleghi, B. (2014). A study on the negative effects of social networking sites such as facebook among asia pacific university scholars in Malaysia. International Journal of Business and Social Science, 5(10), 133-145.

Akbiyik, C. (2013). Effects of social networks on social life of undergraduate students. Middle Eastern \& African Journal of Educational Research, 4(6). Retrieved from

http://majersite.org/issue6/1akbiyik.p df.

Azwar, S. (2008). Penyusunan skala psikologi. Yogyakarta: Pustaka Pelajar.

Banfield, S., \& McCabe, M. (2002). An evaluation of the construct of body image. Adolescence 37(146), 373-393.

Branden, N. (2001). The psychology of selfesteem: A revolutionary approach to selfunderstanding that launched a new era in modern psychology. New York: Nash publishing.

Bryant, R. (2001). What kind of space is cyberspace?. Minerva - An Internet Journal of Philosophy, 5: 138-155.

Cash, T. (2004). Body image: Past, present, and future. Body Image 1(1), 1-5. doi: 10.1016/S1740-1445(03)00011-1

Cash, T., Fleming, E., Alindogan, J., Steadman, L., \& Whitehead, A. (2002b). Beyond body image as trait: the development and validation of the body image states scale. Eating Disorders 10(1), 103-113. doi: $10.1080 / 10640260290081678$
Cash, T. (2002a). MBSRQ user's manual. (3 ${ }^{\text {rd }}$ ed.). Norfolk, VA: Old Dominion University Press.

Cast, A., \& Burke, P. (2002). A theory of self esteem. Social Forces, 80 (3),10411068.

El-Khouly, M. (2015). Study on the use and impact of online social networking in egypt. Journal of Emerging Technologies in Web Intelligence, 7(1), 85-90. doi: 10.7763/IJET.2013.V5.517

Goffman, E. (1956). The presentation of self in everyday life. Edinburgh: University of Edinburgh, Social Sciences Research Centre.

Gonzalez, A., \& Hancock, J. (2011). Mirror, mirror on my facebook wall: Effects of exposure to facebook on selfesteem. Cyberpsychology, Behavior, and Social Networking, 14(1-2), 79-83. doi: 10.1089/cyber.2009.0411

Hamilton, S. (2008). A relationship between perceived body image and depression: How college women see themselves may affect depression. Student Journal of Psychological Science, 1(1), 13-20.

Hogan, J., \& Strasburger, V. (2009). Body image, eating disorders, and the media marjorie. Adolesc Med 19(2008) 521-546. Retrieved from https://researchgate.net/publication/ 24025314

Ikachoi, D., Mberia, K., \& Ndati, N. (2015). Self-esteem as a mediator between social media and communication skills: A case study of undergraduate students at St. Augustine University of Tanzania, Mwanza Campus. International Journal od Scientific and Research Publications, 5(8), 1-6. Retrieved from http://www.ijsrp.org Jones, E., \& Pittman, S. (1982). Toward a general theory of strategic self- 
presentation. Dalam Jery Suls (Eds.), Psychological perpectives on the self, (pp. 231-262). London: Lawrence Erlbaum Associates.

Khairunnisa. (2014). Dampak aplikasi instagram terhadap perilaku konsumtif remaja dalam berbelanja online di kalangan siswa-siswi SMA Negeri 2 Tenggarong. eJournal lmu Komunikasi, 2(4), 220-230. Retrieved from http://ejournal.ikom/fisipunmul.ac.id

Kircaburun, K. (2016). Self-esteem, daily internet use and social media addiction as predictors of depression among Turkish adolescents. Journal of Education and Practice, 7(24), 64-72. Retrieved from http://www.iiste.org

Leif, D., Isak, B., Ida, N., Linda, H., Magdalena, T., Malin, W., ... \& Emelie, D., (2012). Sweden's Largest Facebook Study. Gothenburg: Gothenburg Research Institute.

Lewis, A., \& Neighbors, C. (2005). Self Determination and the use of selfpresentation strategies. The Journal of Social Psychology, 145(4), 469-489.

Mehdizadeh, S. (2010). Self-presentation 2.0: Narcissism and self-esteem on facebook. Cyberpsychology, Behavior, and Social Networking, 13(4), 357-364. doi: $10.1089 /$ cyber.2009.0257

Oxford Dictionary. (2003). Oxford learners dictionary. Oxford: Oxford University Press.

Rosenberg, M., Schooler, Carmi., S, C., \& Rosenberg, F. (1995). Global selfesteem and specific self-esteem: Different concepts, different outcomes. American Sociological Review, 60(1), 141-156. Retrieved from http://jstor.org/stable/2096350

Raymer, K. (2015). The effects of social media sites on self-esteem. (Tesis tidak terpublikasi). Rowan University, New Jersey.

Ryan, R., \& Brown, K. (2003). Why we don't need self esteem: On fundamental needs, contingent love, and mindfulness. Psychological Inquiry 14(1), 27-82.

Sharma, S., \& Sahu, D. (2013). Effect of social networking sites on self confidence. International Journal of Information and Computation Technology, 3(11), 1211-1216. Retrieved from http://www. irphouse.com /ijict.html

Stefanone, M., Lackaff, D., \& Rosen, D. (2011). Contingencies of self-worth and social-networking-site behavior. Cyberpsychology, Behavior, and Social Networking, 14(1-2), 41-49. doi: 10.1089/cyber.2010.004

Suler, J. (2004). The online disinhibition effect. Cyberpsychology \& Behavior, 7(3), 321-326. doi: 10.1089/ 10949310 41291295.

Syamsoedin, W., Bidjuni, H., \& Wowiling, F. (2015). Hubungan durasi penggunaan media sosial dengan kejadian insomnia pada remaja di SMA Negeri 9 Manado. EJournal Keperawatan, 3(1), 1-10. Retrieved from dari http://id.portalgaruda.org/?ref=brow se\&mod=viewarticle\&article $=292474$.

Tafarodi, R., \& Swann, W. (2001). Two dimensional self-esteem: theory and measurement. Personality and Individual Differences, 31(2001), 653673. Retrieved from http://elsevier.com/locate 